\title{
Therapeutic effect of fenugreek (Trigonella foenum-graecum) seeds extract against arsenic induced toxicity in Charles Foster rats
}

\author{
Vikas Kumar \\ Anugrah Narayan College, Patna (Bihar), India \\ Vivek Akhouri \\ Anugrah Narayan College, Patna (Bihar), India \\ Sushil Kumar Singh \\ Anugrah Narayan College, Patna (Bihar), India \\ Arun Kumar* iD \\ Mahavir Cancer Sansthan and Research Centre, Patna (Bihar), India \\ *Corresponding author. Email: drarunk31@gmail.com
}

\section{Article Info}

https://doi.org/10.31018/ jans.v13i3.2899

Received: August 3, 2021

Revised: September 7, 2021

Accepted: September 11, 2021

\section{How to Cite}

Kumar, V. et al. (2021). Therapeutic effect of fenugreek (Trigonella foenum-graecum) seeds extract against arsenic induced toxicity in Charles Foster rats. Journal of Applied and Natural Science, 13(3), 1083 - 1093. https://doi.org/10.31018/jans.v13i3.2899

\begin{abstract}
The prime objective of the present study was to establish fenugreek (Trigonella foenum-graecum L.) seeds extract as an antidote against arsenic induced hepato-renal toxicity in rats. The male Charles Foster rats (weighing 160-180 g) were selected to make arsenic intoxicated model. The arsenic treated group of rats were orally treated with sodium arsenite at the dose of $8 \mathrm{mg} /$ $\mathrm{kg}$ body weight/day for 90 days. Thereafter, the arsenic pretreated rats were further administered with fenugreek ethanolic seeds extract at the dose of $250 \mathrm{mg} / \mathrm{kg}$ body weight/day for 90 days. After the completion of the treatment, animals of all the groups were sacrificed for the biochemical and histopathological estimation. The arsenic treated rats showed significant $(p<$ $0.0001)$ alterations at the various hepatic and renal biomarker parameters and at serum MDA levels in comparison to the control rats. Significant $(p<0.0001)$ arsenic accumulation was also observed in the blood, liver and kidney tissues of the arsenic treated rats. However, after the administration with fenugreek seeds extract, significant $(p<0.0001)$ restoration was observed in the liver and kidney biomarker parameters and at haematological variables. Fenugreek seeds extract administration also significantly $(p<0.0001)$ reduced the serum MDA levels and arsenic concentration levels in blood, liver and kidney tissues, along with considerable restorations at the cellular architecture of liver and kidney tissues. The study concluded that fenugreek seeds possessed potential hepato-renal ameliorative effect against sodium arsenite induced toxicity in rats, and can be used for its therapeutic value against arsenic poisoning.
\end{abstract}

Keywords: Arsenic, Charles Foster rats, Fenugreek (Trigonella foenum-graecum L.), Hepato-Renal toxicity, Lipid peroxidation

\section{INTRODUCTION}

In the entire world, an estimated 300 million people are exposed to arsenic toxicity. Arsenic poisoning in the groundwater has caused severe health hazards in the population (Chakraborti et al., 2018). In Bihar, 18 out of 38 districts are severely affected, exposing nearly 10 million people to groundwater arsenic contamination. Most of the arsenic affected districts in the state are from the Gangetic flood plain region (Chakraborti et al., 2003). The people living in these arsenic affected areas have been reported with several skin manifestations (keratosis, melanosis, raindrop pigmentation, etc.), gastrointestinal disorders, hormonal imbalance, general body weakness, reproductive disorders and cancer
(Kumar et al., 2015a).

Arsenic is present naturally in both organic and inorganic forms in the environment. Trivalent arsenic (arsenite) is more toxic to humans as compared to pentavalent arsenic (arsenate). The trivalent form of arsenic travels into the cells through aquaglyceroporins (Liu et al., 2001). Due to high lipid solubility, trivalent compounds are absorbed more rapidly than their pentavalent form (Ellenhorn et al., 1997). The ingested soluble form of arsenic is very easily absorbed from the gastrointestinal tract into the bloodstream and gets distributed to various organs such as the liver, kidney, lungs and skin (Hunter et al., 1942). Among the various organs, liver and kidney are the major target organ for arsenic induced toxicity, because they play vital role in 
metabolism and excretion, respectively (Ratnaike, 2003). Several studies reported that during arsenic metabolism, cells generate reactive oxygen species (ROS) and free radicals, which damage the cellular macromolecules and disrupt the cellular signaling pathways that play role in arsenic-mediated disease manifestation (Barai et al., 2017; Sohini, 2007). In addition, chronic inorganic arsenic exposure also enhances the susceptibility of the cells to chromosomal aberration, oxidative stress, cell proliferation and inhibiting the DNA repair process, ultimately leading to cancer (Bhattacharya, 2019).

Presently, there are very meagre antidotes available for arsenic toxicity. Hence there is an immense need for the development of safe and effective drugs. The development of a nutritional supplement or drug discovery approach to this problem is a novel initiative (Singh et al., 2007). The secondary metabolites and phytoconstituents from the plant sources are being explored for the novel drug development and diet supplement. One such potential plant source is fenugreek (Trigonella foenum-graecum L.) which belongs to Fabaceae family. The phytochemical screening of fenugreek seeds showed the presence of alkaloids, flavonoids, saponins, free amino acids, proteins, glycosides and mucilaginous fibers (Wani and Kumar, 2018). Several pharmacological properties of fenugreek seeds such as antidiabetic, antioxidative, hypocholesterolemic, antiulcerogenic, antineoplastic, antipyretic, anti-inflammatory, anti-toxic, immunomodulatory and antitumor have been reported (Wani and Kumar, 2018).

Therefore, this study was designed and planned to evaluate the therapeutic potential of fenugreek ethanolic seeds extract against arsenic induced liver and kidney toxicity in Charles Foster rats.

\section{MATERIALS AND METHODS}

\section{Chemicals}

Arsenic was used as sodium (meta) arsenite (90\%) manufactured by Sigma-Aldrich, USA (CAS Number: 7784-46-5; S7400-100G), Lot\# SLBH5736V, PCode 1001683292 was purchased from the licensed and approved scientific store present in Patna, Bihar, India.

\section{Preparation of ethanolic extract of fenugreek (Trigonella foenum-graecum) seeds}

Fenugreek seeds were purchased from the local market of Patna, Bihar and identified by Dr. Sushil Kr Singh (Botanist), Associate Professor, Department of Biotechnology, A. N. College Patna, Bihar, India. The International Plant Names Index (IPNI) Life Sciences Identifier (LSID) number of fenugreek ( $T$. foenum-graecum L.), is 58514-3 (IPNI, 1753). The plant seeds were properly washed through running tap water and dried in the incubator at $37^{\circ} \mathrm{C}$ temperature. After that, the dried seeds were ground into a fine powder, which was further soaked in absolute ethanol for 48 hours. The ethanolic extract was separated by using rota vapour apparatus (Buchi, R-3, Switzerland). The ethanolic extract dose was calculated after LD $_{50}$ estimation, and the final dose was titrated to $250 \mathrm{mg} / \mathrm{kg}$ body weight.

\section{Animals}

Twenty-four healthy male Charles Foster rats ( 8 weeks old) weighing 160-180 $\mathrm{g}$ were used for this study. The rats were provided by the animal house of Mahavir Cancer Sansthan and Research Centre, Patna, India (CPCSEA Reg-No. 1129/bc/07/CPCSEA). The animal experimentation work was approved by the Institutional Animal Ethics Committee (IAEC) of Mahavir Cancer Santhan and Research Centre, Patna, Bihar with the IAEC No. 2017/1F-10/08/17. All rats were acclimatized to laboratory housing conditions under 12-hour light and dark cycles (room temperature maintained at $24 \pm$ $2^{\circ} \mathrm{C}$ ) for 15 days prior to the beginning of the treatment under standard laboratory conditions. These experimental rats were housed in conventional polypropylene cages and stainless-steel grill top having 2 rats in each cage. Food (self-prepared by the laboratory) and water to rats were provided ad libitum.

\section{Experimental design}

Rats were randomly separated into the following groups:

Group I: Control $(n=6)$ - Rats were used as control.

Group II: Arsenic treated $(n=6)$ - Rats were orally treated with sodium arsenite ( $8 \mathrm{mg} / \mathrm{kg}$ body weight/day) for 90 days.

Group III: Arsenic pretreated control $(n=6)$ - Rats were orally treated with sodium arsenite $(8 \mathrm{mg} / \mathrm{kg}$ body weight/day) for 90 days and left without any treatment up to next 90 days for auto recovery observation.

Group IV: Fenugreek administration $(n=6)$ - Rats were orally administered fenugreek (Trigonella foenumgraecum) ethanolic seeds extract $(250 \mathrm{mg} / \mathrm{kg}$ body weight/day) for 90 days upon the arsenic pretreated rats ( $8 \mathrm{mg} / \mathrm{kg}$ body weight/day for 90 days).

After the completion of the entire treatment, rats were anesthetized by diethyl ether and sacrificed. Blood samples were collected in EDTA- coated and plane vacutainer through the orbital puncture from all the groups. Serum was extracted for the various biochemical estimations. The liver and kidney tissues were also dissected out for the histopathological study and arsenic concentration determination.

\section{Haematological parameters assay}

The whole blood collected in EDTA-coated vacutainer was used for haematological estimation. The red blood cells (RBC), haemoglobin (HGB), Haematocrit (HCT), Mean corpuscular haemoglobin $(\mathrm{MCH})$, Mean corpus- 
Kumar, V. et al. / J. Appl. \& Nat. Sci. 13(3), 1083 - 1093 (2021)

cular volume (MCV), platelets (PLT) and white blood cells (WBC) were immediately analyzed by using fully automated haematological analyzer (BC-2800, Mindray, China).

\section{Biochemical parameters assay}

The various Liver and Kidney biochemical parameters such as serum glutamate pyruvate transaminase (SGPT), serum glutamate oxaloacetate transaminase (SGOT), alkaline phosphatase (ALP), total bilirubin, urea, creatinine, uric acid, and albumin were assayed using standard Kit manufactured by Coral Clinical Systems, India, through (UV - Vis) spectrophotometer (UV10, Thermo Scientific, USA).

\section{Lipid peroxidation (LPO) assay}

Thiobarbituric acid reactive substances (TBARS), as a marker of LPO, were evaluated through the double heating method (Draper HH, Hadley, 1990). The method is based on the principle of spectrophotometric measurement of color reproduced in reaction with thiobarbituric acid (TBA) and malondialdehyde (MDA). For this study, $2.5 \mathrm{~mL}$ of $100 \mathrm{~g} / \mathrm{L}$ solution of trichloroacetic acid (TCA) was mixed with $0.5 \mathrm{~mL}$ serum in a centrifuge tube and heated in the water bath at $90^{\circ} \mathrm{C}$ for 15 minutes. After cooling at room temperature, the mixture was further allowed to centrifuge at $3000 \mathrm{rpm}$ for 10 minutes, and $2 \mathrm{~mL}$ of the supernatant was mixed with 1 $\mathrm{mL}$ of $6.7 \mathrm{~g} / \mathrm{L}$ TBA solution in test tube which was further heated in water bath at $90^{\circ} \mathrm{C}$ for 15 minutes and left for cooling at the room temperature. Thereafter, absorbance was measured by UV - Visible spectrophotometer (UV-10, Thermo Scientific USA) at $532 \mathrm{~nm}$.

Arsenic concentration determination in blood, liver and kidney tissues

The whole blood, liver and kidney tissue samples were utilized for arsenic estimation using Atomic Absorption Spectrophotometer. The blood and tissue samples were digested using concentrated $\mathrm{HNO}_{3}$ on a hot plate under the fume hood and estimated as per the protocol of $\mathrm{NIOSH}$ (1994) and the concentration was read through Graphite Furnace Atomic Absorption Spectrophotometer (Pinnacle 900T, Perkin Elmer, Singapore) at Mahavir Cancer Sansthan and Research Centre, Patna, Bihar.

\section{Histopathological study}

For the histopathological study, liver and kidney tissues were dissected from all the groups of rats and washed in normal saline, grossed into small pieces and finally fixed in $10 \%$ formalin for 24 hours. The tissue samples were moved for the dehydration process, through series of ethanol concentration and finally embedded into paraffin. Thin sections of $5 \mu \mathrm{m}$ thickness were cut by digital rotary microtome (Microm HM 340E, Thermo
Scientific USA) and stained with hematoxylin and eosin (H\&E) for the analysis of histopathological changes under light microscope.

\section{Statistical analysis}

Results are presented as mean \pm standard deviation (SD) for six rats in each group. Total variation was represented in a set of data and was analyzed through one-way analysis of variance (ANOVA) followed by Tukey test with multiple comparisons. The value $p<$ 0.05 was considered as statistically significant. Calculations were performed with the GraphPad Prism program (GraphPad 5.0 Software, Inc., San Diego, USA).

\section{RESULTS}

\section{Effects on the haematological parameters in rats}

The haematological parameters showed that there were significant $(p<0.0001)$ changes in the RBC, HGB, HCT, WBC and platelets $(p<0.05)$ counts, while there were non-significant changes in the MCV and $\mathrm{MCH}$ levels in the arsenic treated group in comparison to the control group. Moreover, in arsenic pretreated control group, which was left for auto recovery for 90 days after arsenic administration, had a significant $(p<$ 0.05 ) decrease in the WBC counts and non-significant changes observed in RBC, HGB, HCT, MCV, MCH and platelets counts in comparison to the arsenic treated group. However, significant $(p<0.0001)$ restoration were observed in the RBC, HGB, HCT and WBC count, while non-significant changes were observed in the $\mathrm{MCV}, \mathrm{MCH}$ and platelets count in the fenugreek seeds extract treated group in comparison to the arsenic pretreated control group (Table 1).

\section{Effect on the arsenic concentration in blood, liver and kidney tissues of rats}

The results showed that the arsenic treated group had significant $(p<0.0001)$ arsenic accumulation in the blood, liver and kidney tissues compared to the control group. Moreover, in the arsenic pretreated control group, which was left for auto recovery for 90 days after arsenic administration, had significant $(p<0.0001)$ reduction in the arsenic concentration (accumulation) in blood, liver and kidney tissues in comparison to the arsenic treated group. Furthermore, fenugreek seeds extract administration upon arsenic pretreated rats resulted in significant $(p<0.0001)$ reduction in the arsenic concentration in blood, liver and kidney tissues in comparison to the arsenic pretreated control group (Table 2).

\section{Effects on the serum hepatic biomarker parameters in rats}

The results showed that, arsenic treated rats had significant $(p<0.0001)$ increase in the serum SGPT, 
Kumar, V. et al. / J. Appl. \& Nat. Sci. 13(3), 1083 - 1093 (2021)

Table 1. Haematological parameters in control and treatment groups of rats

\begin{tabular}{|c|c|c|c|c|}
\hline Parameters & Control & Arsenic treated & $\begin{array}{l}\text { Arsenic pretreated } \\
\text { control }\end{array}$ & $\begin{array}{l}\text { Fenugreek } \\
\text { administration }\end{array}$ \\
\hline $\mathrm{RBC}\left(\times 10^{6} / \mathrm{mm}^{3}\right)$ & $8.46 \pm 1.12$ & $3.78 \pm 1.17^{* x}$ & $4.91 \pm 1.63^{\text {ns }}$ & $8.68 \pm 0.78^{\# \#}$ \\
\hline HGB $(g / d L)$ & $14.32 \pm 0.84$ & $7.80 \pm 1.42^{* * *}$ & $9.33 \pm 1.29^{\mathrm{ns}}$ & $15.57 \pm 1.38^{\# \#}$ \\
\hline HCT (\%) & $39.77 \pm 2.42$ & $20.83 \pm 4.46^{* * *}$ & $26.23 \pm 4.21^{\mathrm{ns}}$ & $43.03 \pm 3.78^{\# \#}$ \\
\hline $\operatorname{MCV}(f L)$ & $47.55 \pm 6.44$ & $56.73 \pm 8.70^{\mathrm{ns} \dagger}$ & $58.78 \pm 12.41^{\mathrm{ns}}$ & $49.55 \pm 1.50^{\mathrm{ns} \dagger \dagger}$ \\
\hline $\mathrm{MCH}(\mathrm{pg})$ & $17.10 \pm 2.22$ & $21.65 \pm 4.89^{\mathrm{ns} \dagger}$ & $20.50 \pm 5.81^{\mathrm{ns}}$ & $17.88 \pm 0.44^{\mathrm{nst \dagger}}$ \\
\hline WBC $\left(\times 10^{3} / \mathrm{mm}^{3}\right)$ & $8.46 \pm 1.77$ & $14.05 \pm 2.08^{* * *}$ & $11.23 \pm 1.28^{\wedge}$ & $7.01 \pm 1.01^{\# \# \#}$ \\
\hline Platelets $\left(\times 10^{3} / \mathrm{mm}^{3}\right)$ & $728.8 \pm 106.1$ & $452.3 \pm 160.2^{*}$ & $615.5 \pm 150.0^{\mathrm{ns}}$ & $778.0 \pm 167.1^{\mathrm{ns} \dagger+}$ \\
\hline
\end{tabular}

Haematological parameters in different treated group (control and treatment groups). Values are expressed as mean $\pm \mathrm{SD}, \mathrm{n}=6 ;{ }^{* * *}(p<$ $0.0001),{ }^{*}(P<0.05),{ }^{n s t}$ (non-significant) compared with control group; ${ }^{\wedge}(p<0.05),{ }^{\text {ns }}$ (non-significant) compared with arsenic treated group; ${ }^{\# \#}(p<0.0001),{ }^{\text {nstt }}$ (non-significant) compared with arsenic pretreated control group

Table 2. Levels of arsenic concentration in control and treatment groups of rats tissues

\begin{tabular}{|c|c|c|c|c|}
\hline Parameters & Control & Arsenic treated & $\begin{array}{l}\text { Arsenic pretreated } \\
\text { control }\end{array}$ & $\begin{array}{l}\text { Fenugreek ad- } \\
\text { ministration }\end{array}$ \\
\hline Blood $(\mu \mathrm{g} / \mathrm{L})$ & $0.23 \pm 0.07$ & $133.4 \pm 5.05^{* \star *}$ & $81.28 \pm 7.03^{\wedge \wedge}$ & $11.11 \pm 3.42^{\# \# \#}$ \\
\hline Liver $(\mu \mathrm{g} / \mathrm{kg})$ & $0.91 \pm 0.16$ & $174.0 \pm 6.24^{\star \star \star}$ & $110.3 \pm 7.55^{\wedge \wedge \wedge}$ & 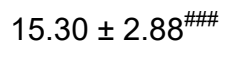 \\
\hline Kidney ( $\mu \mathrm{g} / \mathrm{kg})$ & $0.42 \pm 0.13$ & $96.57 \pm 5.04^{\star \star \star}$ & $76.38 \pm 4.83^{\wedge \wedge \wedge}$ & $32.14 \pm 4.20^{\# \# \#}$ \\
\hline
\end{tabular}

Arsenic concentration levels in different treated group of rats' tissues (control and treatment groups); Values are expressed as mean \pm $\mathrm{SD}, \mathrm{n}=6 ;{ }^{* * *}(p<0.0001)$ compared with control group; ${ }^{\wedge \wedge}(p<0.0001)$ compared with arsenic treated group; ${ }^{\prime \prime \prime \#}(p<0.0001)$ compared with arsenic pretreated control group

SGOT, ALP and total bilirubin levels in comparison to the control group. However, arsenic pretreated control group rats, which were left for auto recovery for 90 days after arsenic administration, had significant $(p<$ $0.0001)$ decrease in the SGPT, SGOT, total bilirubin and ALP $(p<0.05)$ levels in comparison to the arsenic treated group. But, after the administration with fenugreek seeds extract at the dose of $250 \mathrm{mg} / \mathrm{kg}$ body weight per day for 90 days upon arsenic pretreated rats, showed the protective effect against arsenic induced hepatotoxicity as there was significant $(p<$ 0.0001) decrease in the levels of SGPT, SGOT, ALP and total bilirubin in comparison to the arsenic pretreated control group (Figs. 1-4).

\section{Effects on the serum renal biomarker parameters in rats}

In the arsenic treated group rats, there was a significant $(p<0.0001)$ increase in the serum levels of urea, uric acid and creatinine, while there was a significant $(p<$ 0.0001 ) decrease in the serum albumin levels in comparison to the control group. However, arsenic pretreated control group, which was left for auto recovery for 90 days after arsenic administration, had a significant $(p<$ $0.05)$ decrease in the serum levels of urea, uric acid and creatinine $(p<0.0001)$, while the non-significant changes observed in the albumin levels in comparison to the arsenic treated group. But, after the administration with fenugreek seeds extract at the dose of 250 $\mathrm{mg} / \mathrm{kg}$ body weight per day for 90 days upon arsenic pretreated rats, there was significant $(p<0.0001)$ de- crease in the urea, uric acid and creatinine levels, while significant increase $(p<0.0001)$ in the albumin levels were observed as compared to the arsenic pretreated control group, denoting the protective effect of fenugreek seeds against arsenic induced renal toxicity (Figs. 5-8).

\section{Effect on the serum lipid peroxidation (MDA) in rats} In the arsenic treated rats, there was significant $(p<$ 0.0001 ) increase in the serum MDA levels in comparison to the control group. However, in arsenic pretreated control group, which was left for auto recovery for 90 days after arsenic administration had significant ( $p<$ 0.001 ) decrease in the serum MDA levels. But, after administration with fenugreek seeds extract at the dose of $250 \mathrm{mg} / \mathrm{kg}$ body weight per day for 90 days upon arsenic pretreated rats, there was significant $(p<$ 0.0001 ) decrease in the serum MDA levels in comparison to the arsenic pretreated control group, denoting the antioxidant activity of fenugreek seeds (Fig. 9).

\section{Histopathological study of liver}

In the histopathological study, the control group rat liver section showed normal architecture of central vein with hepatocytes well arranged in the sinusoids (Fig. 10A). The arsenic treated rat liver section showed significant degeneration of hepatocytes, dilatation in sinusoids and haemorrhage in portal vein (Fig. 10B). The arsenic pretreated control rat liver section also showed high degree of dilatation and vacuolizations in sinusoids along with congestion in the portal vein and hepatic arteries 


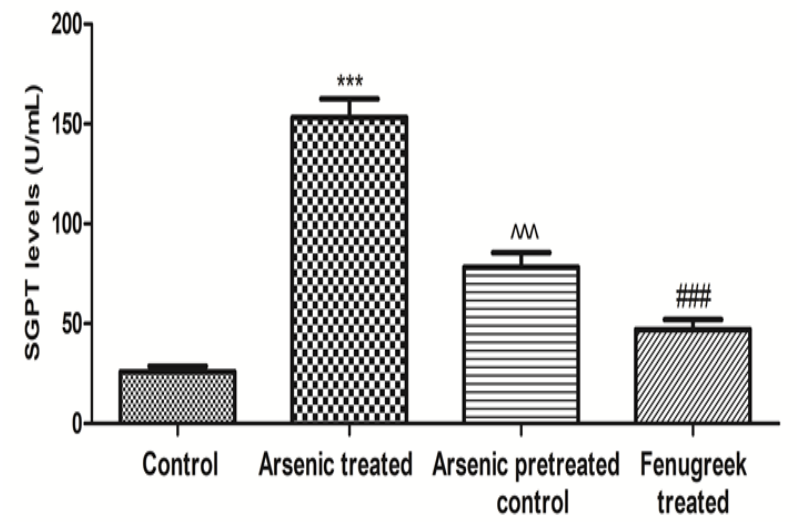

Fig. 1. SGPT levels in different treated groups (control and treatment group). Values are expressed as mean $\pm S D$, $n=6 ;{ }^{* * *}(p<0.0001)$ compared with control group; ${ }^{\wedge \wedge \wedge}(p<$ $0.0001)$ compared with arsenic treated group; ${ }^{\prime}(p<$ 0.0001) compared with arsenic pretreated control group

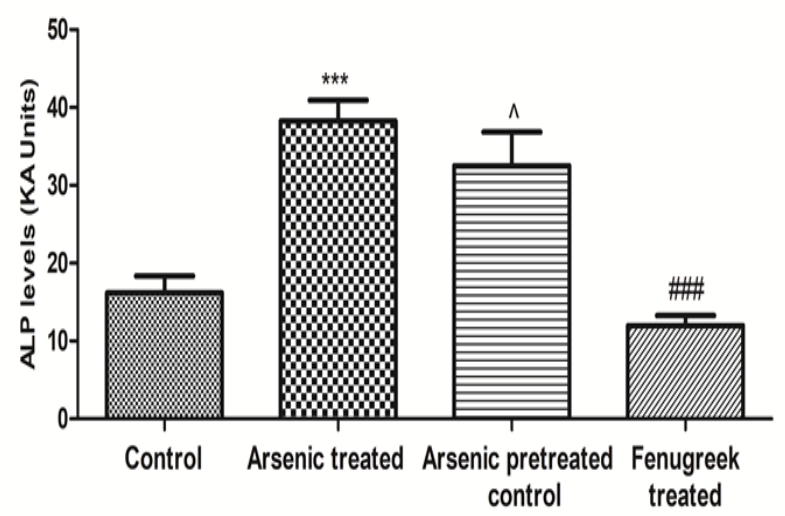

Fig. 3. ALP levels in different treated groups (control and treatment group). Values are expressed as mean $\pm S D$, $n=6 ;{ }^{* * *}(p<0.0001)$ compared with control group; $\wedge(p<$ $0.05)$ compared with arsenic treated group; ${ }^{\# \#}(p<0.0001)$ compared with arsenic pretreated control group

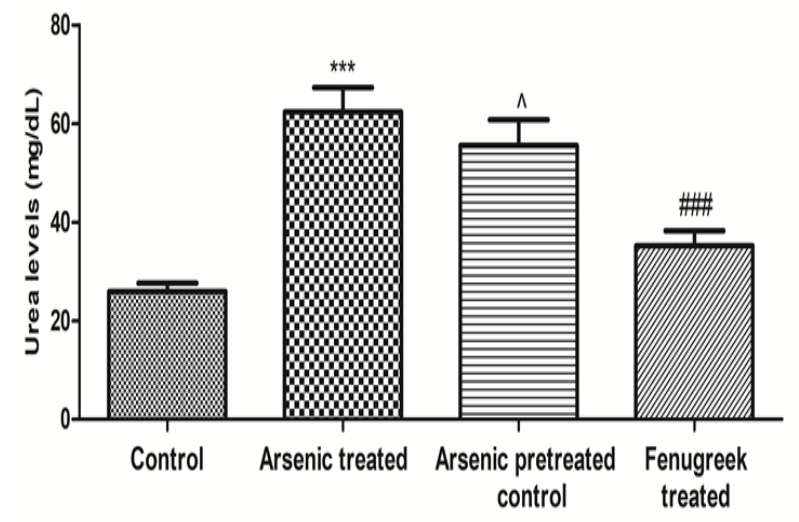

Fig. 5. Urea levels in different treated groups (control and treatment group). Values are expressed as mean $\pm S D$, $n=6 ;{ }^{* * *}(p<0.0001)$ compared with control group; $\wedge(p<$ $0.05)$ compared with arsenic treated group; ${ }^{\# \#}(p<0.0001)$ compared with arsenic pretreated control group

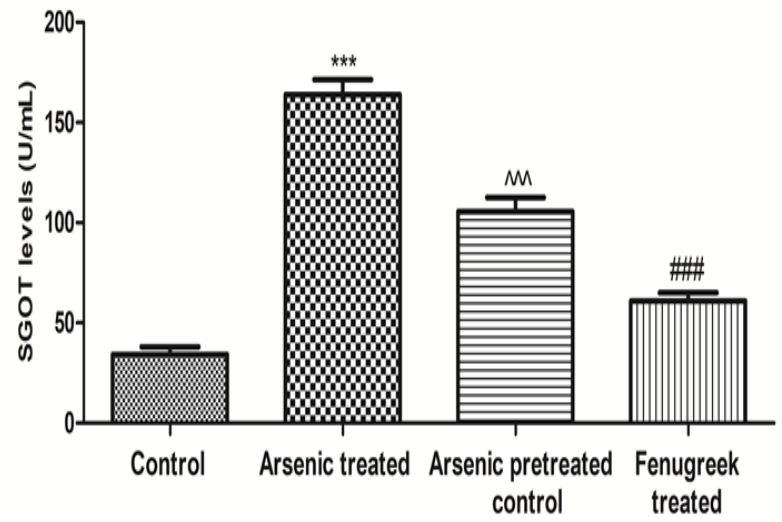

Fig. 2. SGOT levels in different treated groups (control and treatment group). Values are expressed as mean \pm $S D, n=6 ;{ }^{* * *}(p<0.0001)$ compared with control group; $\wedge \wedge \wedge$ $(p<0.0001)$ compared with arsenic treated group; ${ }^{\# \#}(p<$ 0.0001) compared with arsenic pretreated control group

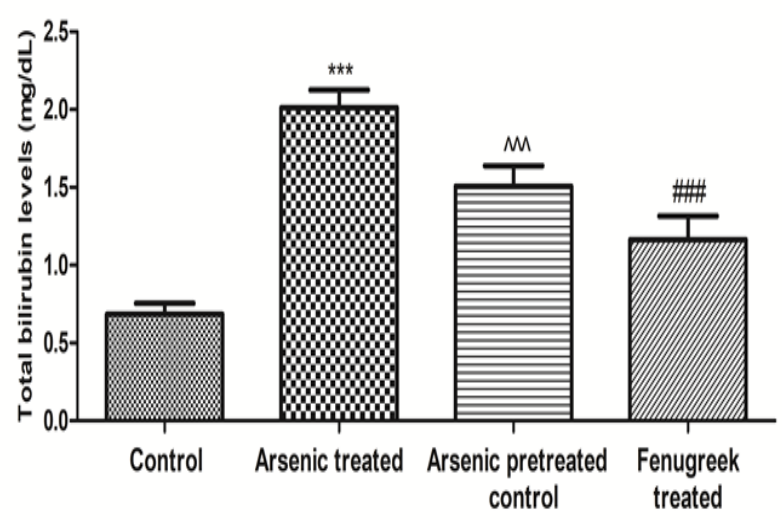

Fig. 4. Total bilirubin levels in different treated groups (control and treatment group). Values are expressed as mean $\pm S D, n=6 ;{ }^{* * *}(p<0.0001)$ compared with control group; ${ }^{\wedge \wedge \wedge}(p<0.0001)$ compared with arsenic treated group; ${ }^{\# \# ~}(p<0.0001)$ compared with arsenic pretreated control group

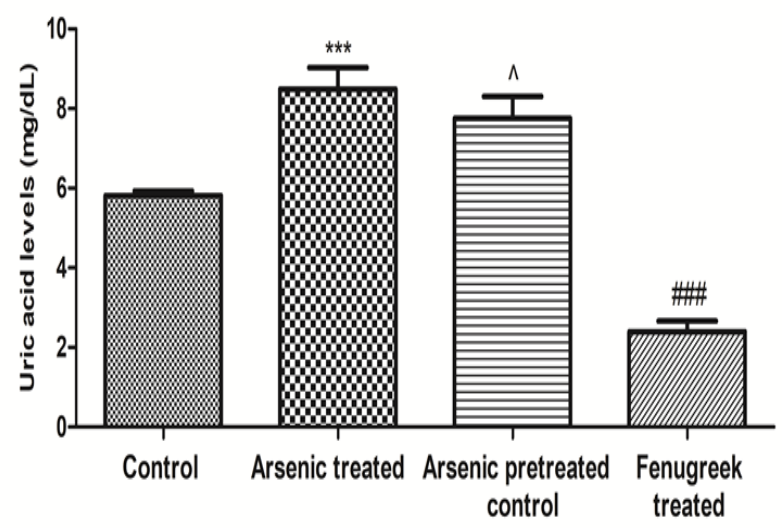

Fig. 6. Uric acid levels in different treated groups (control and treatment group). Values are expressed as mean \pm $S D, n=6 ;{ }^{* * *}(p<0.0001)$ compared with control group; $\wedge^{\wedge} p$ $<0.05)$ compared with arsenic treated group; \#\# $(p<$ 0.0001) compared with arsenic pretreated control group 


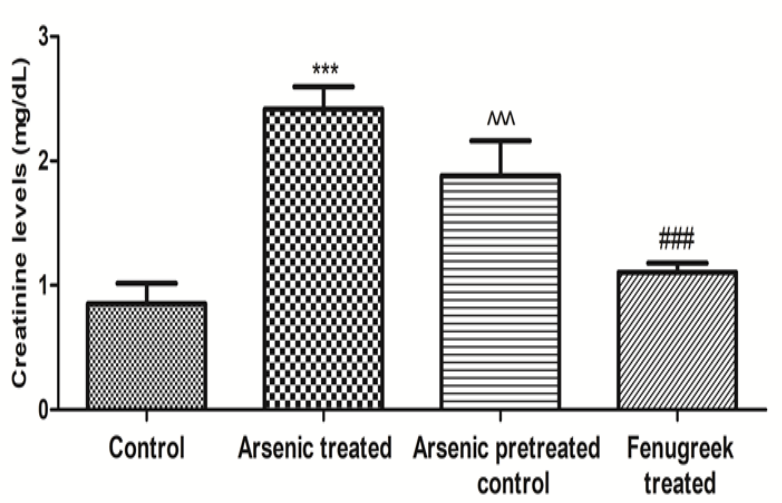

Fig. 7. Creatinine levels in different treated groups (control and treatment group). Values are expressed as mean $\pm S D, n=6 ;{ }^{* * *}(p<0.0001)$ compared with control group; ${ }^{\wedge \wedge}(p<0.0001)$, compared with arsenic treated group; \#\# ( $p$ 0.0001) compared with arsenic pretreated control group

which denotes no auto repair mechanism in the cells (Fig. 10C). The fenugreek seeds extract administration upon arsenic pretreated rat liver section showed significant restoration in the hepatocytes along with the mild degeneration in portal vein, which was almost recovered from the deleterious effect of arsenic toxicity (Fig. 10D).

\section{Histopathological study of kidney}

In this histopathological study, control rat kidney section showed normal architecture of glomerulus in Bowman's capsule (Fig. 11A). The arsenic treated rat kidney section showed degeneration in glomerulus; vacuolization in Bowman's capsule along with distal and proximal convoluted tubules (Fig. 11B). The arsenic pretreated control rats also showed persistence of degeneration in nephrocytes, glomerulus and Bow-

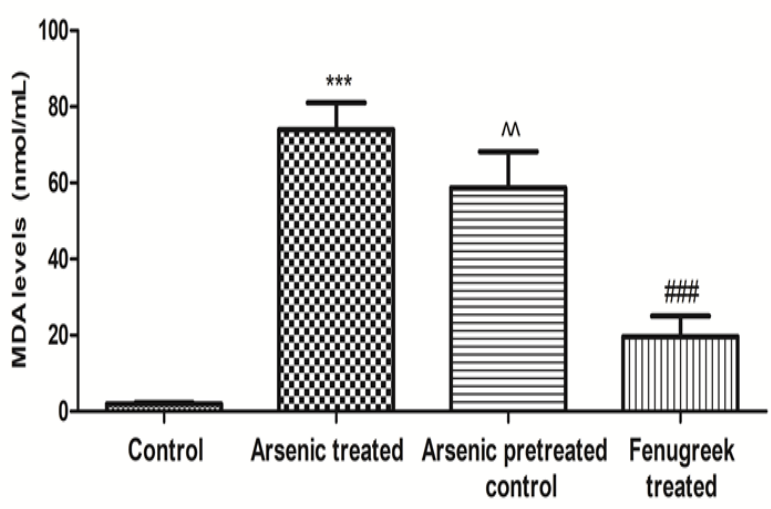

Fig. 9. Lipid peroxidation (MDA) levels in different treated groups (control and treatment group). Values are expressed as mean $\pm S D, n=6 ;{ }^{* * *}(p<0.0001)$ compared with control group; ${ }^{\wedge \wedge}(p<0.001)$ compared with arsenic treated group; ${ }^{\# \#}(p<0.0001)$ compared with arsenic pretreated control group

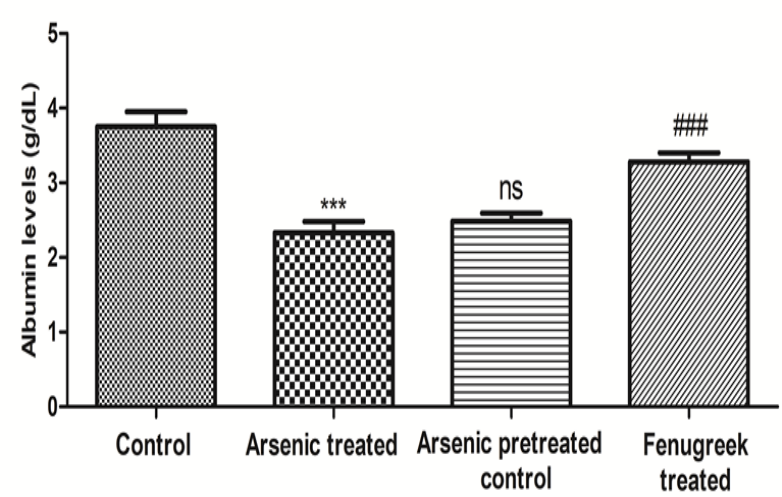

Fig. 8. Albumin levels in different treated groups (control and treatment group). Values are expressed as mean \pm $S D, n=6 ;{ }^{* * *}(p<0.0001)$ compared with control group; ${ }^{n s}$ (non-significant) compared with arsenic treated group; $(p<0.0001)$ compared with arsenic pretreated control group

man's capsule as well as vacuolization and haemorrhage in renal convoluted tubules which indicates no auto amelioration from arsenic intoxication (Fig. 11C). The fenugreek seeds extract administration upon arsenic pretreated rat kidney section showed significant restoration in the glomerulus and Bowman's capsule along with the persistence of mild vacuolization in distal and proximal convoluted tubules compared to arsenic treated rat's kidney section (Fig. 11D).

\section{DISCUSSION}

Prolonged exposure to arsenic is known to cause several toxic effects involving multiple organ systems with complex mechanisms. Arsenic is a well-known toxicant that affects hematological parameters like platelets, $\mathrm{HGB}, \mathrm{RBC}, \mathrm{WBC}, \mathrm{HCT}, \mathrm{MCV}$ and $\mathrm{MCH}$. The present study showed significant changes in RBC, HGB, HCT, WBC and platelets counts after arsenic treatment. OlaDavies and Akinrinde, (2016) suggested that prolong arsenic exposure owing to accumulation in erythrocytes leads to a reduction in $\mathrm{RBC}$ and $\mathrm{HGB}$ as a result of inhibition of porphyrin or heme synthesis. Elevated levels of WBC count indicate damage due to severe physical stress, infection of the body and toxic exposure, and leukemia (Kumar et al., 2013). Additionally, in this study, change in platelets counts indicated that arsenic inhibited the production of thrombopoietin. The finding indicates that chronic arsenic exposure causes severe damage to the liver that may have caused inhibition of thrombopoietin production, resulting in a decrease in the platelets count (Wu et al., 2014; PeckRadosavljevic et al., 2000; 1997). Although, after the administration of fenugreek seeds extract, significant improvement in the hematological parameters - RBC, WBC, HGB, HCT levels were observed. Fenugreek seeds extract also improved liver functions and may 

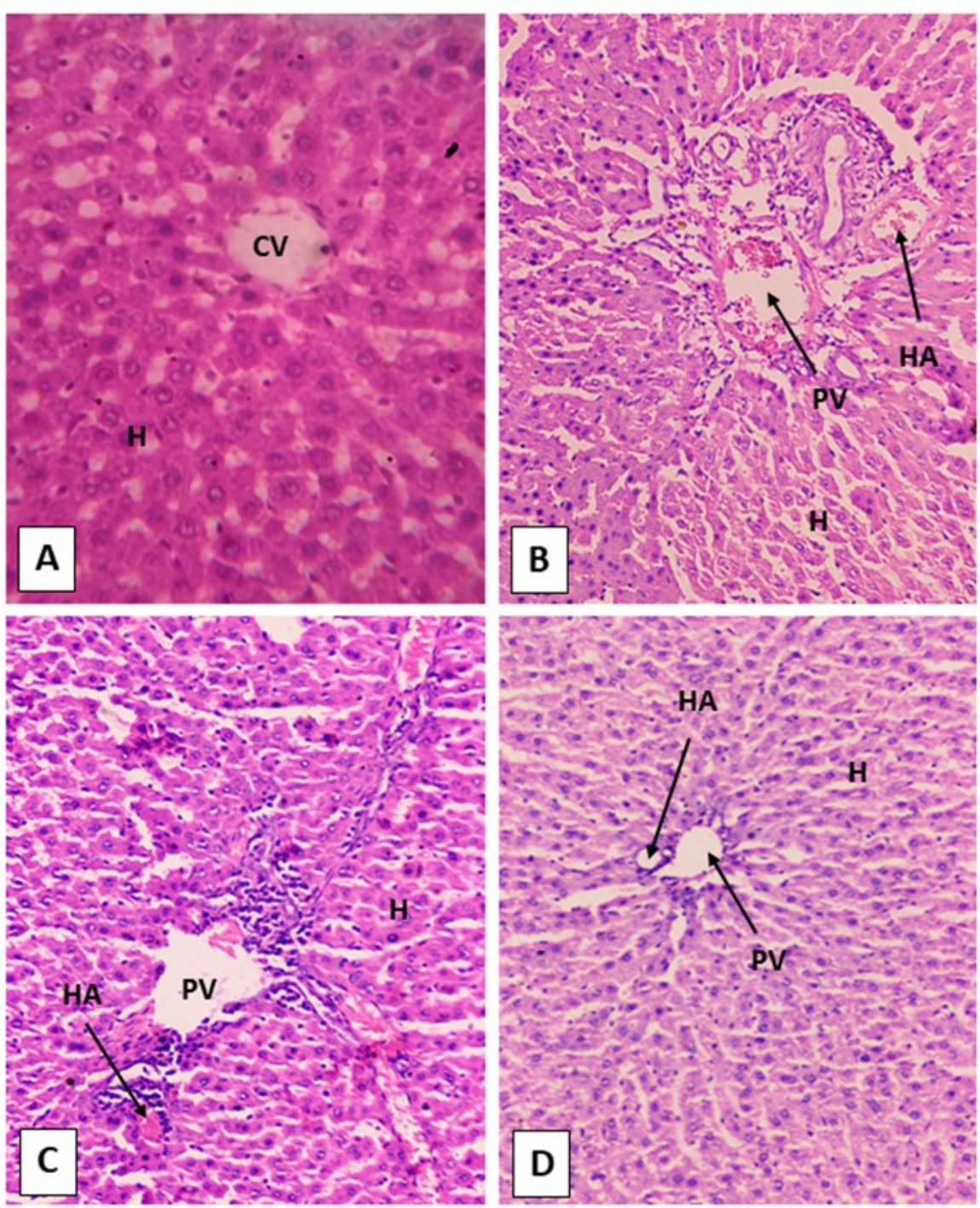

Fig. 10. Microphotograph of rat liver stained with hematoxylin and eosin (H\&E X500). (A) Section of control rat liver showing normal arrangement of hepatocytes (H) \& the central vein (CV) (H\&E X500). (B) Section of arsenic treated rat liver showed degenerated hepatocytes and with haemorrhage in portal vein (PV) and hepatic arteries (HA) (H\&E X500). (C) Section of arsenic pretreated control rat liver with still persistence of degeneration and vacuolization in the hepatocytes $(H)$ along with the congestion in hepatic arteries and portal vein (PV) due to arsenic toxicity (H\&E X500). (D) Section of liver administered with fenugreek extract upon arsenic pretreated rat showing significant amelioration in the hepatic histoarchitecture along with potal vein (PV) and hepatic arteries (HA) (H\&E X500).

also have increased the efficiency of iron storage and regulation of the proper hemoglobin synthesis. The liver also produced the thrombopoietin, which stimulated the platelets production (Mbarki et al., 2017; Ahmed et al., 2013).

Arsenic interferes with the normal functioning of the vital organs such as the liver and kidney (GomezCaminero et al., 2001). The liver is the major site of glutathione activity which detoxifies arsenic (Beesley, 2018; Hedayati, 2016; Ratnaike, 2003). Methylated forms of trivalent arsenic causes liver toxicity through interaction with DNA and protein of the hepatocytes that in turn reduces methylation efficiency leading to the damage to hepatocytes and spill out hepatic biomarker enzymes such as SGPT, SGOT, ALP and total bilirubin (Sharma et al., 2014; Klaassen and Watkins 1984). In this study, there was a significant increase in SGPT, SGOT, ALP and total bilirubin after the arsenic treatment. Due to the loss of hepato-cellular function and loss of membrane integrity. The significant liver biochemical markers change can be correlated with liver histopathology. The hepatocellular architecture of the arsenic treated group showed hepatocytes degeneration with vacuolizations in sinusoids and haemorrhage in the portal vein. These results were consistent with the previous findings on arsenic and the increased oxidative stress in rats (Kumar et al., 2015b; Mershiba et al., 2013). In contrast, after the administration of fenugreek seeds extract upon arsenic intoxicated rats, a significant decrease in the hepatic biomarker parame- 

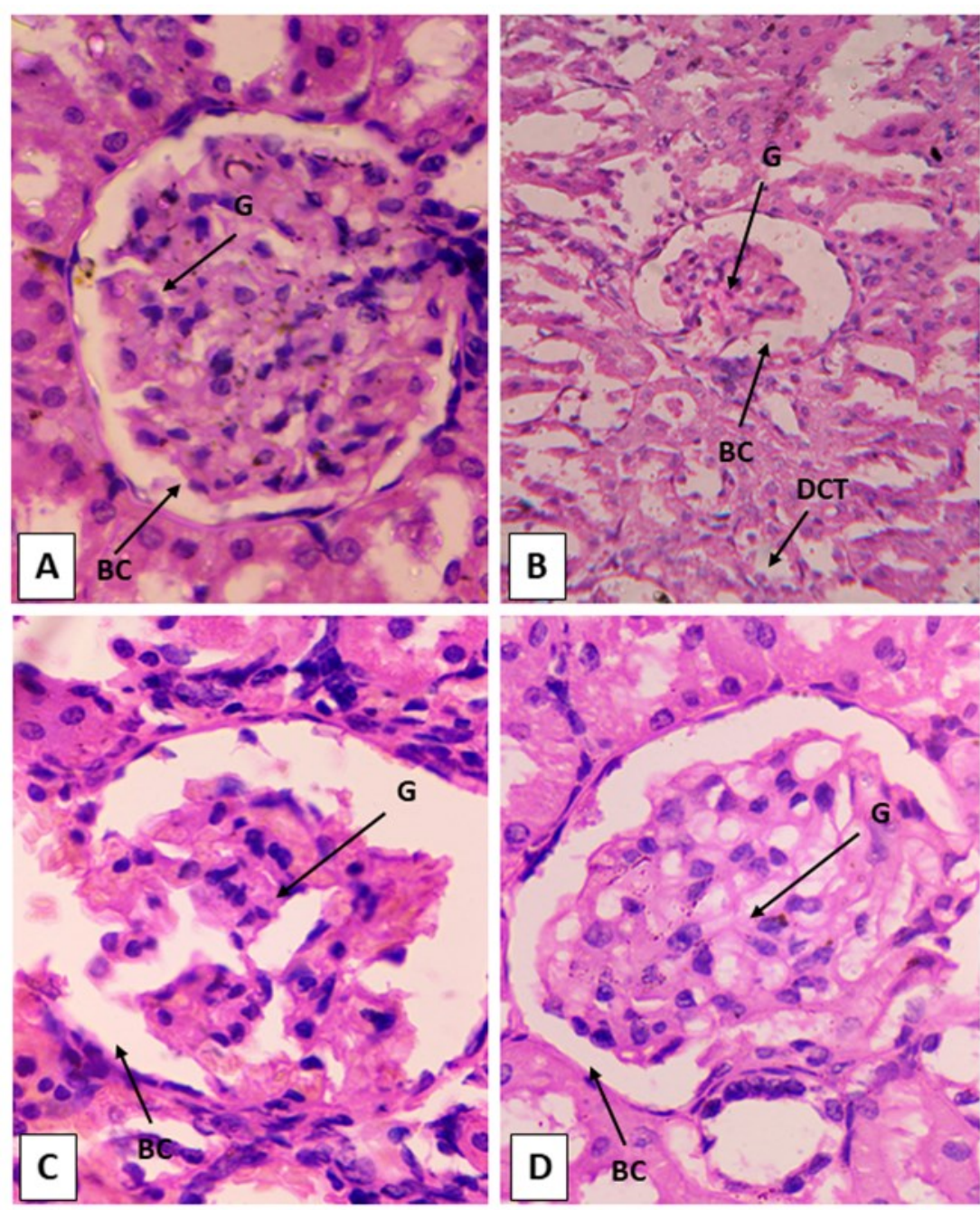

Fig. 11. Microphotograph of rat kidney stained with hematoxylin and eosin (H\&E). (A) Section of control rat kidney showing normal architecture of Bowman's capsule (BC) and glomerulus (GM) (H\&E X800). (B) Arsenic treated rat kidney section showing degeneration in glomerulus (GM), significant vacuolization in Bowman's capsule (BC) basement and in proximal and distal convoluted tubules (PCT and DCT) (H\&E X500). (C) Arsenic pretreated control rat kidney section showed degeneration in the Bowman's capsule (BC) and glomerulus (GM) along with haemorrhage in renal convoluted tubule denotes that there was no significant recovery in the nephrocytes (H\&E X800). (D) The Fenugreek extract adminstraion upon arsenic pretreated rat kidney section showed significant restoration in the glomerulus (GM) and Bowman's capsule (BC) along with the proximal and distal convoluted tubules (PCT and DCT) (H\&E X800).

ters - SGPT, SGOT, ALP and total bilirubin levels were observed, which denote its ameliorative property. They also stabilize the hepatocellular membrane and the histological alterations. Presently, quercetin and naringenin are the most active components of polyphenol flavonoids present in fenugreek (Shang et al., 1998), which inhibits the expression and signaling pathways by transforming growth factor- $\beta-1$ (TGF- $\beta-1$ ) and the synthesis of connective tissue proteins in activated hepatic stellate cells (HSCs) (Kang et al., 2001; Mao et al., 2004). The result of the present study suggests that the fenugreek seeds polyphenols and flavonoids play a significant role in mitigating the arsenic induced hepatotoxicity.

Various studies demonstrate that arsenic toxicity also causes renal damage. In case of chronic arsenic expo- sure, after passing through the liver in the form of monomethylarsonic acid and dimethylarsinic acids, it reaches the kidney where they are filtered through glomerulus and are reabsorbed subsequently into the proximal tubules. And, if they remain in the tubular cells, they cause tubular damage (Rizwan et al., 2014; Wang et al., 2014; Peraza et al., 2006). Renal injury due to arsenic intoxication can be assayed by the serum levels of urea, uric acid, creatinine and albumin. In the present study, significant alterations were observed in urea, uric acid, creatinine and albumin levels in the serum of arsenic treated rats. The histopathological study also showed very high degree of degeneration in nephrocytes, Bowman's capsule, glomerulus, distal convoluted tubule and proximal convoluted tubule. These biochemical and histopathological alterations 
denote renal failure due to arsenic toxicity. The observations are consistent with other reports of arsenic induced toxicity on rodent models (Sinha and Manna, 2008; Majhi et al., 2011; Kumar et al., 2015b; Mershiba et al., 2013).

After the administration with fenugreek seeds extract upon arsenic treated rats, there was a significant restoration in the kidney at the biochemical and cellular levels. The biochemical parameters reflected very significant normalization in the urea, uric acid, creatinine and albumin levels, while at the cellular level, the normalization in nephrocytes architecture and in their function was observed. This result illustrates the membrane stabilizing nature of fenugreek seeds extract as previously reported (Belaïd-Nouira et al., 2013). The antioxidant activity of fenugreek, mentioned in various studies, is considered to be exerted by polyphenols, especially flavonoids. Xue et al. (2011) reported that fenugreek seeds were able to restore the renal function of diabetic rats, through its antioxidant activity. A recent study by Uslu et al. (2019) also reported that fenugreek seeds normalizes serum marker and improves the histological changes against sodium nitrite intoxication in kidney and liver damage.

Increasing MDA levels is the most important sign of oxidative (LPO) damage in cells. In the present study, a significant increase in the serum MDA levels was observed in arsenic treated rats, which were reported in earlier studies (Kumar et al., 2015b, c). Other studies revealed that arsenic toxicity caused a significant increase in the rate of formation of reactive oxygen species (ROS) such as hydrogen peroxide, superoxide anion radical and hydroxyl radical (Shi et al., 2004). ROS can lead to lipid peroxidation and degradation of the bilayer matrix of membrane lipid, resulting in deactivation of membrane-bound receptors and increased tissue permeability (Adil et al., 2015). However, after the administration with fenugreek seeds extract, there was a significant reduction in the MDA levels compared to arsenic intoxicated rats. The present study results suggest that fenugreek polyphenols play a significant role in mitigating the LPO abnormalities against arsenic -induced toxicity. Previous studies have also shown that fenugreek seeds are a rich source of polyphenols such as quercetin, apigenin, tricine, vitexin and kaempferol (Kenny et al., 2013; Benayad et al., 2014). Fenugreek extract has been found to reduce lipid peroxidation and countered antioxidant status in blood and various organs in diabetic rats (Ravikumar and Anuradha, 1999; Genet et al., 2002). The present study indicated that fenugreek seeds have rich flavonoids that effectively reduce oxidative damage in arsenic intoxicated rats.

Arsenic accumulation in the tissues and blood is a serious health concern to people living in arsenic exposed areas. High arsenic accumulation causes damage to the vital organs of our body with the rise of several diseases, including cancer. Chronic arsenic exposure leads to arsenic accumulation in various organs such as liver, kidney, heart, lungs, muscles and spleen (Sayed et al., 2015; Dua et al., 2015; Ratnaike, 2003). In the present study, a significant high arsenic accumulation was observed in the liver, kidney and blood of the arsenic treated group compared to the control group. The increased arsenic level denotes the high arsenic accumulation in the blood, liver and kidney tissue caused by chronic arsenic exposure. The results are in line with the studies from several other researchers, who have also observed high arsenic accumulation in the blood, liver and kidney tissues upon high arsenic exposure (Al-Forkan et al., 2016; De et al., 2016; Tandon et al., 2012; Nain and Smits, 2012). The liver, the primary organ responsible for arsenic metabolism, had higher arsenic accumulation than the kidney and blood. Hence, this study indicates that high level chronic arsenic exposure causes increased arsenic accumulation in the body's vital organs such as the liver and kidney, resulting in disrupted arsenic metabolism and excretion. However, the fenugreek seeds extract seems to play a significant role in controlling the arsenic contamination in the blood as well as in liver and kidney tissues. Hence, fenugreek extract played a significant role in controlling arsenic poisoning in chronic arsenic exposed experimental animals. Therefore, it can be recommended as a suitable antidote and therapeutic drug against arsenic toxicity in future.

\section{Conclusion}

The present study concluded that ethanolic extract of fenugreek ( $T$. foenum-graecum L.) seeds possesses potential hepato-renal protection against arsenic induced toxicity in Charles Foster rats. The fenugreek seeds also possessed antitoxic effect against arsenic induced toxicity at the biochemical and cellular levels. Hence, the present study will develop a fenugreekbased therapeutic drug in the future as a novel drug against arsenic toxicity for the exposed human population.

\section{ACKNOWLEDGEMENTS}

The authors are thankful to Anugrah Narayan College, Patna, Bihar, India, for infrastructural facilities; and Mahavir Cancer Sansthan and Research Center, Patna, Bihar, India, for the animal and laboratory facilities.

\section{Conflict of interest}

The authors declare that they have no conflict of interest. 


\section{REFERENCES}

1. Adil, M., Kandhare, A. D., Visnagri, A. \& Bodhankar, S. L. (2015). Naringin ameliorates sodium arsenite-induced renal and hepatic toxicity in rats: decisive role of KIM-1, Caspase-3, TGF- $\beta$, and TNF- $\alpha$. Ren Fail, 37(8),13961407, doi: 10.3109/0886022X.2015.1074462

2. Ahmed Fadel Elseed A. M., Danil, T., Abu ElgaimAtta Elmanan, B. \& Hassan, Ali O. (2013). Effects of fenugreek (Trigonella foenum-graecum) seeds saponin on digestibility, N-retention, Hematological parameters and blood Metabolites in Rabbits. World's Vet. J., 3(3), 65-73.

3. Al-Forkan, M., Islam, S., Akter, R., Shameen Alam, S., Khaleda, L., Rahman, Z. \& Salma Chowdhury, D.U. (2016). A sub-chronic exposure study of arsenic on hematological parameters, liver enzyme activities, histological studies and accumulation pattern of arsenic in organs of Wistar albino rats. J Cytol Histol, S.5(2).

4. Barai, M., Ahsan, N., Paul, N., Hossain, K., Rashid, M.A., Kato, M., Ohgami, N. \& Akhand, A.A. (2017). Amelioration of arsenic-induced toxic effects in mice by dietary supplementation of Syzygium cumini leaf extract. Nagoya $\mathrm{J}$ Med Sci, 79(2),167-177, doi: 10.18999/nagjms.79.2.167

5. Beesley, S. Chemicals, Metals and the Liver, Sarah Beesley. (n.d.). 2018. https://selfhealclinic.co.nz/chemicalsmetals-and-the-liver/

6. Belaïd-Nouira, Y., Bakhta, H., Haouas, Z., Flehi-Slim, I. \& Cheikh, H.B. (2013). Fenugreek seeds reduce aluminum toxicity associated with renal failure in rats. Nutr Res Pract, 7(6), 466-474, doi.org/10.4162/nrp.2013.7.6.466

7. Benayad, Z., Gómez-Cordovés, C. and Es-Safi, N.E. (2014). Characterization of flavonoid glycosides from fenugreek (Trigonella foenum-graecum) crude seeds by HPLC-DAD-ESI/MS analysis. Int. J. Mol. Sci., 15(11),206 68-206685, doi:10.3390/ijms151120668

8. Bhattacharya, A.K. (2019). Arsenic contamination in the groundwater of West Bengal, Jharkhand and Bihar with a special fFocus on the stabilization of arsenic-laden sludge from arsenic filters. EJGE, 24, 01-23.

9. Chakraborti, D., Mukherjee, S.C., Pati, S., Sengupta, M.K., Rahman, M.M., Chowdhury, U.K., Lodh, D., Chanda, C.R., Chakraborti, A.K. \& Basu, G.K. (2003). Arsenic groundwater contamination in Middle Ganga Plain, Bihar, India: a future danger?. Environ. Health Perspect., 111(9), 1194-1201, doi: 10.1289/ehp.5966

10. Chakraborti, D., Singh, S.K., Rahman, M.M., Dutta, R.N., Mukherjee, S.C., Pati, S. \& Kar, P.B. (2018). Groundwater arsenic contamination in the Ganga River Basin: a future health danger. Int. J. Environ Res. Public Health, 15(2), 180, doi: 10.3390/ijerph15020180.

11. De, A., Nath, S., Bandyopadhyay, S.K., Mandal, T.K. \& Das, A.K. (2016). Ameliorative effects of Bauhinia acuminata $\mathrm{L}$ stem bark powder against chronic arsenicosis in rats. Toxicol. Environ. Health Sci., 8(3), 258-262, doi.org/10.1007/s13530-016-0283-z

12. Draper, H.H \& Hadley, M. (1990) Malondialdehyde determination as index of lipid Peroxidation. In Methods in enzymology Jan 1 (Vol. 186, pp. 421-431). Academic press.

13. Dua, T.K., Dewanjee, S., Gangopadhyay, M., Khanra, R., Zia-Ul-Haq, M. \& De Feo, V. (2015). Ameliorative effect of water spinach, Ipomea aquatica (Convolvulaceae), against experimentally induced arsenic toxicity. J Transl
Med, 1;13(1), 81, doi: 10.1186/s12967-015-0430-3.

14. Ellenhorn, M.J., Schonwald, S., Ordog, G. \& Wasserberger, I. (1997) Ellenhorn's. Medical Toxicology: Diagnosis and Treatment of Human Poisoning. 2nd ed. Baltimore, MD: Williams and Wilkins. 1739-1764.

15. Genet, S., Kale, R.K. \& Baquer, N.Z. (2002). Alterations in antioxidant enzymes and oxidative damage in experimental diabetic rat tissues: effect of vanadate and fenugreek (Trigonella foenum graecum). Mol Cell Biochem, 236(1-2):7-12, doi: 10.1023/a:1016103131408.

16. Gomez-Caminero, A., Howe, P.D., Hughes, M., Kenyon, E., Lewis, D.R., Moore, M., Aitio, A., Becking, G.C. \& Ng, J. (2001) Arsenic and arsenic compounds, environmental health criteria. World Health Organization, Geneva. vol 224.

17. Hedayati, A. (2016). Liver as a target organ for ecotoxicological studies. J Coast Zo Manage, 19:1-2, doi:10.4172/2473-3350.1000e118

18. Hunter, F.T., Kip, A.F. \& Irvine, J.W. (1942). Radioactive tracer studies on arsenic injected as potassium arsenite I. Excretion and localization in tissues. Journal of Pharmacology and Experimental Therapeutics, 76(2):207-220.

19. International Plant Names Index (IPNI). (1753) The Herbarium Catalogue, Royal Botanic Gardens, Kew, Trigonella foenum-graecum | International Plant Names Index (ipni.org).

20. Kang, L.P., Qi, L.H., Zhang, J.P., Shi, N., Zhang, M., Wu, T.M. \& Chen, J. (2001). Effect of genistein and quercetin on proliferation, collagen synthesis, and type I procollagen mRNA levels of rat hepatic stellate cells. Acta Pharmacologica Sinica, 22(9), 793-796.

21. Kenny, O., Smyth, T.J., Hewage, C.M. and Brunton, N.P. (2013). Antioxidant properties and quantitative UPLC-MS analysis of phenolic compounds from extracts of fenugreek (Trigonella foenum-graecum) seeds and bitter melon (Momordica charantia) fruit. Food Chem., 141(4), 4295 -4302, doi.org/10.1016/j.foodchem.2013.07.016

22. Klaassen, C.D. \& Watkins, J.B. (1984) Mechanisms of bile formation, hepatic uptake, and biliary excretion. Pharmacol Rev, 36(1),1-67.

23. Kumar, A., Ali, M., Kumar, R., Suman, S., Kumar, H., Nath, A., Singh, J.K. \& Kumar, D. (2013) Withania somnifera protects the haematological alterations caused by Sodium arsenite in Charles foster rats. Int $J$ Res Ayurveda Pharm, 4, 491-494, doi:10.7897/2277-4343.04405

24. Kumar, A., Ali, M., Rahman, M.S., Iqubal, A., Anand, G., Niraj, P.K. \& Kumar, R., (2015b). Antidote effects of plants of Himalayan sub-origin against arsenic induced toxicity. $J$ Bio Chem Res, 2:99-109.

25. Kumar, A., Ali, M., Rahman, S.M., Iqubal, A.M., Anand, G., Niraj, P.K., Shankar, P. \& Kumar, R. (2015a). Ground water arsenic poisoning in "Tilak Rai Ka Hatta" village of Buxar district, Bihar, India causing severe health hazards and hormonal imbalance. J Environ Anal Toxicol, 5(4),1-7, doi: 10.4172/2161-0525.1000290

26. Kumar, A., Kumar, R., Rahman, M.S., lqubal, M.A., Anand, G., Niraj, P.K. \& Ali, M. (2015c) Phytoremedial effect of Withania somnifera against arsenic-induced testicular toxicity in Charles Foster rats. Avicenna $J$ Phytomed, 5(4), 355.

27. Liu, S.X., Athar, M., Lippai, I., Waldren, C. \& Hei, T.K. (2001). Induction of oxyradicals by arsenic: implication for 
mechanism of genotoxicity. Proc. Natl. Acad. Sci., 98(4), 1643-1648, doi: 10.1073/pnas.031482998

28. Majhi, C.R., Khan, S., Leo, M.D.M., Manimaran, A., Sankar, P. \& Sarkar, S.N. (2011). Effects of acetaminophen on reactive oxygen species and nitric oxide redox signaling in kidney of arsenic-exposed rats. Food Chem Toxicol, 49(4):974-982, doi: 10.1016/j.fct.2011.01.003.

29. Mao, Y.Q., Liu, X.J., Jiang, Y. \& Wu, H.B. (2004). Effect of quercetin on the signal pathway of TGFbeta1 in activated hepatic stellate cells. Journal of Sichuan University, Medi Sci Edi, 35(6), 802-805.

30. Mbarki, S., Alimi, H., Bouzenna, H., Elfeki, A. \& Hfaiedh, N. (2017). Phytochemical study and protective effect of Trigonella foenum graecum (Fenugreek seeds) against carbon tetrachloride-induced toxicity in liver and kidney of male rat. Biomed Pharmacother, 88,19-26, doi: 10.1016/ j.biopha.2016.12.078

31. Mershiba, S.D., Dassprakash, M.V. \& Saraswathy, S.D. (2013). Protective effect of naringenin on hepatic and renal dysfunction and oxidative stress in arsenic intoxicated rats. Mol Biol Rep, 40(5), 3681-3691, doi: 10.1007/ s11033-012-2444-8

32. Nain, S. \& Smits, J.E. (2012) Pathological, immunological and biochemical markers of subchronic arsenic toxicity in rats. Environ. Toxicol., 27(4), 244-254, doi: 10.1002/tox.20 635

33. NIOSH (National Institute for Occupational Safety and Health). (1994) Elements in blood or tissue. Method: 8005. In: NIOSH manual of analytical methods. 4 Edn. O.H. Cincinnati: Department of Health and Human Service, National Institute of Occupational Safety and Health. DHHS publication, 94-113.

34. Ola-Davies, O.E. \& Akinrinde, A.S. (2016). Acute sodium Arsenite-induced hematological and biochemical changes in wistar rats: Protective effects of ethanol extract of Ageratum conyzoides. Pharmacognosy Res., 8(1), 26, doi 10.4103/0974-8490.178645

35. Peck-Radosavljevic, M., Wichlas, M., Zacherl, J., Stiegler, G., Stohlawetz, P., Fuchsjäger, M., Kreil, A., MetzSchimmerl, S., Panzer, S., Steininger, R. and Mühlbacher, F. (2000). Thrombopoietin induces rapid resolution of thrombocytopenia after orthotopic liver transplantation through increased platelet production. Blood. The Journal of the American Society of Hematology, 95(3),795-801.

36. Peck-Radosavljevic, M., Zacherl, J., Meng, Y.G., Pidlich, J., Lipinski, E., Längle, F., Steininger, R., Mühlbacher, F. \& Gangl, A. (1997). Is inadequate thrombopoietin production a major cause of thrombocytopenia in cirrhosis of the liver? J. Hepatol., 27(1), 127-131, doi: 10.1016/s01688278(97)80291-7

37. Peraza, M.A., Cromey, D.W., Carolus, B., Carter, D.E. \& Gandolfi, A.J. (2006). Morphological and functional alterations in human proximal tubular cell line induced by low level inorganic arsenic: evidence for targeting of mitochondria and initiated apoptosis. J. Appl. Toxicol., 26(4), 356367, doi: 10.1002/jat.1149

38. Ratnaike, R.N. (2003). Acute and chronic arsenic toxicity. Postgrad Med. J., 79, 391-396, doi: 10.1136/pmj.79.9 33.391

39. Ravikumar, P. \& Anuradha, C.V. (1999) Effect of fenugreek seeds on blood lipid peroxidation and antioxidants in diabetic rats. Phytother. Res., 13(3),197-201, doi: 10.1002/(SICI)1099-1573(199905)13:3<197::AID-PTR 413>3.0.CO;2-L

40. Rizwan, S., Naqshbandi, A., Farooqui, Z., Khan, A.A. \& Khan, F. (2014). Protective effect of dietary flaxseed oil on arsenic-induced nephrotoxicity and oxidative damage in rat kidney, Food. Chem. Toxicol., 68, 99-107, doi: 10.1016/j.fct.2014.03.011

41. Sayed, S., Ahsan, N., Kato, M., Ohgami, N., Rashid, A. \& Akhand, A.A. (2015). Protective effects of Phyllanthus emblica leaf extract on sodium arsenite-mediated adverse effects in mice. Nagoya J .Med. Sci., 77(1-2),145.

42. Shang, M., Cai, S., Han, J., Li, J., Zhao, Y., Zheng, J., Namba, T., Kadota, S., Tezuka, Y. \& Fan, W. (1998). Studies on flavonoids from fenugreek (Trigonella foenumgraecum L). Zhongguo Zhong Yao Za Zhi. Chin J mete Medi, 23(10), 614-639.

43. Sharma, B., Singh, S. \& Siddiqi, N.J. (2014). Biomedical implications of heavy metals induced imbalances in redox systems. Biomed. Res. Int, 640754, doi: $10.1155 / 2014 / 640754$

44. Shi, H., Shi, X. \& Liu, K.J. (2004). Oxidative mechanism of arsenic toxicity and carcinogenesis. Mol Cell Biochem, 255(1-2):67-78, doi: 10.1023/b:mcbi.0000007262.260 44. e8

45. Singh, N., Kumar, D. \& Sahu, A.P. (2007). Arsenic in the environment: effects on human health and possible prevention. J. Environ. Biol., 28(2), 359-365

46. Sinha, M., Manna, P. \& Sil, P.C. (2008). Arjunolic acid attenuates arsenic-induced nephrotoxicity. Patho, 15 (3):147-156, doi: 10.1016/j.pathophys.2008.03.001

47. Sohini, Rana, S.V. (2007). Protective effect of ascorbic acid against oxidative stress induced by inorganic arsenic in liver and kidney of rat. Indian J. Exp. Biol. 45(4), 371-375

48. Tandon, N., Roy, M., Roy, S. \& Gupta, N. (2012). Protective effect of Psidium guajava in arsenic-induced oxidative stress and cytological damage in rats. Toxicol. Int., 19(3), 245, doi: 10.4103/0971-6580.103658.

49. Uslu, G.A., Hamit, Uslu. \& adali, Y. (2019). Hepatoprotective and nephroprotective effects of Trigonella foenumgraecum L. (Fenugreek) seed extract against sodium nitrite toxicity in rats. Biomed Res. Ther., 6, 3142-3150, doi: 10.15419/bmrat.v6i5.540

50. Wang, X., Zhao, H., Shao, Y., Wang, P., Wei, Y., Zhang, W., Jiang, J., Chen, Y. \& Zhang, Z. (2014). Nephroprotective effect of astaxanthin against trivalent inorganic arsenic-induced renal injury in wistar rats. Nut. Res. Pract, 8 (1),46-53, doi: 10.4162/nrp.2014.8.1.46

51. Wani, S.A. \& Kumar, P. (2018). Fenugreek: A review on its nutraceutical properties and utilization in various food products. J. Saudi Soc. Agric. Sci., 117(2), 97-106, doi: 10.1016/j.jssas.2016.01.007

52. Wu, Y., Dai, J., Zhang, W., Yan, R., Zhang, Y., Ruan, C. and Dai, K. (2014). Arsenic trioxide induces apoptosis in human platelets via $\mathrm{C}$-Jun $\mathrm{NH}$ 2-terminal kinase activation. PloSOne 9:e86445, doi: 10.1371/journal.pone.0 086445

53. Xue, W., Lei, J., Li, X. \& Zhang, R. (2011). Trigonella foenum graecum seed extract protects kidney function and morphology in diabetic rats via its antioxidant activity. Nutr. Res, 31(7),555 - 562, doi:10.1016/j.nutres.2011.0 5.010 